\title{
PUCRS Open University for the Third Age
}

\author{
Mirna Wetters Portuguez' ${ }^{1}$ Newton Luiz Terra² \\ Coordinator of Universidade Aberta da Terceira Idade, Pontifícia Universidade Católica do Rio Grande do Sul (UNATI/PUCRS). Porto Alegre, RS, Brasil. \\ (D) orcid.org/0000-0003-4068-6249 \\ 2 Coordinator of UNATI/PUCRS. Porto Alegre, RS, Brasil. (D) orcid.org/0000-0002-7904-3649
}

M any know there is an evident relationship between life quality in a given society and the excellence of its universities. Proposals and actions that promote social wellbeing are originated in the joint efforts of the university community. This is the case of the Catholic University of Rio Grande do Sul (PUCRS). The University aims at providing solutions to transform the society and positively influence the future of people, contributing towards the growth of the State of Rio Grande do Sul. The advance of knowledge and continuous and progressive improvement of practices and projects of an educational, formative character, in health support is a continuous challenge to ensure a higher degree of social accountability and a supportive commitment, proper to current times.

PUCRS is committed to collaborate for a better future for all, based on justice and respect. The growth in Brazilian third age population is a reality, and is occurring at an unprecedented level. By 2025, Brazil will rank sixth in the number of elder in the world, being surpassed only by China, India, Russia, United States and Japan. In the current year, the population over 60 years of age will be over 32 million persons. The State of Rio Grande do Sul will have a higher rate of death than of births, and consequently a faster aging. According to data from IBGE, $19 \%$ of the State's population is over 60 years of age, corresponding to about 2 million individuals. The human life expectancy in Brazil grows, as well as in almost everywhere else in the world. One century ago, Brazilians use to live 40 years in average. Currently, we live approximately 77 years. Forecasts for 2060 indicate that in the State of Rio Grande do Sul the life expectancy will be approximately 84 years. Men will reach 80.94 years and women 86.90 .

One of the concerns of Geriatrics and Gerontology is also to extend a healthy and dignified life. There is a worldwide concern for people to achieve an active aging, i.e., healthy, participative, safe, productive, with autonomy and independence, so that they age happy, enthusiastically and with vitality, to continue learning and finding out new things. Though there are myths and pre-concepts that stigmatize the elder as incapable of learning, a new conscience is rising regarding the integration of elder in society.

It is important to highlight that elder have what is known as crystallized intelligence, which relates to personal experiences, with the environment and the social reality. It is not reduced with aging, and can progress, as long as there are opportunities. It refers to general and specific knowledge, solving problems 
of daily routine, schooling contents and linguistic competence, and its trend is to be kept or to rise with age.

Aware of the impact of population aging in the State of Rio Grande do Sul, PUCRS has created the Open University for the Third Age (UNATI), aiming at contributing towards the improvement in life quality for people who are facing the aging process, providing guidance and specific health services. It is an informal, permanent education program, targeting aging persons, providing the opportunity to learn contents, values and attitudes, as well as ways of getting to know, to acquire, to use and to apply such knowledge in different situations of daily life. The learning promotes capabilities and abilities that the aging individual needs to develop himself and to remain as a citizen. It seeks to make elder persons absorb knowledge reaching a new level, broadening their vision of the world and their possibilities of insertion.

Its broad objectives are to allow people to access the University as a mean to increase their cultural space, as well as continuous education by providing courses and actions that update knowledge. It also aims at providing to the aging population the practice of activities that allow strengthening their social and political participation, in order to undertake their aging process and enjoying their citizenship in full.

People in the aging process are the target population for this Program, which has as its goals: helping in developing new capabilities; creating opportunities for reinsertion in a process of continuous qualification in varied courses by means of educational, cultural and social activities; contribute towards improvements in life quality and for them to become healthy, productive, useful and participative in the community; contribute for them to learn and find out new motivational interests, new purposes and allowing them to realize their life projects; providing a space that generates coexistence and exchange of experiences; contribute for them to keep themselves socially and intellectually active; cooperate for them to keep or to return to the labor market; providing information that allow thinking about aging and that helps them in promoting social transformations that can be useful to achieve a successful old age; encourage their participation during aging in social, political, economic and cultural activities of their community.

UNATI/PUCRS also intends to avoid the terms "elder" or "old" to be linked to an idea of decadence, incapacity for work and social exclusion. On the contrary, it has been created to provide elder persons with the continuity of a life that is active, independent, productive and pleasurable, so that they can age healthier, with new life projects, more satisfied and happier. 